\title{
Proposta Metodológica para Estimativa do Saldo de Emprego do Comércio Internacional e Aplicação para a Economia Brasileira
}

\section{Methodological Proposal to Estimate Net Employment for International Trade and Application to the Brazilian Economy}

Umberto Antonio Sesso Filho* Rossana Lott Rodrigues** Antonio Carlos Moretto***

Resumo: O objetivo deste estudo é estimar os efeitos do comércio internacional sobre o emprego setorial com base em uma proposta metodológica que usa dados das contas nacionais do Brasil do período entre 1990 e 2003. Os principais resultados mostram que o saldo do emprego do comércio internacional do Brasil foi negativo de 1990 a 2001, mesmo em anos de superávit na balança comercial, por exportar produtos de baixo valor agregado. Os maiores saldos negativos de emprego ocorrem em 1991 e 1997, aproximadamente, 4\% do número de pessoas ocupadas na economia, tornando-se positivo em 2002 e 2003. O Plano Real apresentou um custo-emprego, entre 1994 e 1995, de 1,38 milhão de postos de trabalho, 2,25\% do pessoal ocupado em 1995. O comércio internacional promoveu maior realocação intersetorial do emprego nos anos de 1995, 1999 e 2002.

Palavras-chave: Emprego. Comércio internacional. Contas nacionais. Insumo-produto.

Abstract: The objective of this study was to estimate the effects of the international trade over the sectorial employment based on a methodological proposal that use data of Brazil National Accounts between 1990 and 2003. The main results showed that the balance of employment of the international trade of Brazil was negative during 1990-2001, even in years of surplus in commercial trade, due to export products of low aggregated value. The bigger negative balanced of employment occurred in 1991 and 1997, approximately 4\% of the number of workers in

\footnotetext{
* Professor-doutor do Departamento de Economia da Universidade Estadual de Londrina (UEL). Pesquisador do CNPq. E-mail: umasesso@uel.br

** Professora-doutora do Departamento de Economia da Universidade Estadual de Londrina (UEL). E-mail: rlott@uel.br

*** Professor-doutor do Departamento de Economia da Universidade Estadual de Londrina (UEL). E-mail: acmoretto@uel.br
} 
economy, changing positive in 2002 and 2003. The Plano Real presented a employment cost between 1994/1995 of 1,38 millions jobs, 2,25\% of workers in 1995. The international trade promoted larger inter-sectorial reallocation of employment in the years 1995, 1999 e 2002.

Keywords: Employment. International trade. National accounts. Input-output.

\section{JEL Classification: F16.}

\section{1 lntrodução}

A preocupação com o emprego no Brasil ganhou importância nos anos 1990 em função das grandes transformações ocorridas no período, que poderiam ser resumidas no binômio privatização/abertura comercial. Ambas, ao mesmo tempo, introduziram um choque de modernização e competitividade na economia e refletiram a mudança de paradigma do papel do Estado. As variações da demanda doméstica e aumento do comércio internacional causaram mudanças tecnológicas e reestruturação produtiva da economia brasileira com importantes efeitos sobre a produção, a renda e o emprego.

O período 1990-2003 foi marcado pela abertura comercial, com intensificação do comércio internacional e pelas mudanças do regime da taxa de câmbio, e pode ser dividido em três partes: 1990-1994, 1995-1999 e 2000-2003. Entre 1990 e 1994, ocorreu a abertura comercial marcada pelo impacto das importações sobre uma economia que permaneceu fechada por longo período, mas que apresentava saldo positivo da balança comercial segundo dados obtidos no Instituto de Pesquisa Econômica Aplicada (2010). O período 1995-1999 teve como características principais o regime de câmbio fixo e a valorização da moeda nacional, com déficits da balança comercial. A partir de 1999, teve lugar a desvalorização cambial e o regime foi modificado para câmbio flexível, com melhora da balança comercial (BAER, 2003; GREMAUD; VASCONCELOS; TONETO JR., 2007; SOARES; SERVO; ARBACHE, 2001).

A curto prazo, os custos envolvidos na realocação de recursos e do pessoal ocupado em setores beneficiados e prejudicados pelo fluxo de bens e serviços entre países determinam o aumento do desemprego. Os trabalhadores dispensados necessitam de treinamento para atuar em outras atividades e tempo suficiente para encontrar novos empregos. Porém, a longo prazo, considerando a flexibilidade dos salários e preços e o desenvolvimento de novas habilidades dos trabalhadores, o que se espera é que ocorra a realocação dos ativos físicos e humanos entre setores, levando à diminuição do desemprego (MOREIRA; NAJBERG, 1999).

Diante do cenário descrito, o objetivo da pesquisa é apresentar uma proposta metodológica baseada na ferramenta insumo-produto para estimar o saldo 
emprego do comércio internacional e identificar os principais setores beneficiados ou prejudicados em termos de geração de empregos e aplicá-la para a economia brasileira no período de 1990 a 2003. O artigo está dividido em quatro seções, incluindo a introdução: a proposta metodológica para análise dos efeitos do comércio internacional sobre o emprego é apresentada na segunda seção. Na terceira, os resultados da aplicação da metodologia proposta são resumidos e analisados. A quarta seção traz as conclusões do estudo.

\section{Metodologia}

\subsection{A Matriz de Insumo-Produto}

O modelo de insumo-produto de Leontief é constituído por um sistema de equações lineares, as quais representam a distribuição da produção dentro da economia. No início, procurou-se obter os dados da contabilidade detalhada das transações entre os setores em unidades físicas. Entretanto, devido ao fato de mais de um produto ser vendido por setor, surgiram problemas de mensuração dos fluxos intersetoriais, o que levou à representação da matriz de insumo-produto em termos monetários. O Quadro 1 ilustra as informações do modelo de insumo-produto, que descreve os insumos e as produções dos diferentes setores da economia para um período determinado. As linhas representam a distribuição da produção de cada setor no sistema econômico e as colunas apresentam os insumos absorvidos pelos setores para sua produção. 
Quadro 1 - Matriz de insumo-produto para dois setores

\begin{tabular}{|c|c|c|c|c|c|c|c|c|c|c|}
\hline & \multicolumn{8}{|c|}{ Setores comprad ores ( $\mathrm{j}$ ) } & \multirow{3}{*}{$\begin{array}{l}\text { Valor } \\
\text { bruto } \\
\text { da } \\
\text { produçã }\end{array}$} \\
\hline & & \multicolumn{3}{|c|}{ Demanda intermediária } & \multicolumn{5}{|c|}{ Demanda final } & \\
\hline & & $\begin{array}{c}\text { Setor } \\
1\end{array}$ & $\begin{array}{c}\text { Setor } \\
2\end{array}$ & $\begin{array}{c}\text { Subtotal } \\
\text { (demanda } \\
\text { intermadiária) }\end{array}$ & Consumo & $\begin{array}{c}\text { Investim } \\
\text { ento }\end{array}$ & $\begin{array}{l}\text { Gasto } \\
\text { do } \\
\text { governo }\end{array}$ & Exportações & $\begin{array}{c}\text { Subtota1 } \\
\text { (demanda } \\
\text { final) }\end{array}$ & \\
\hline \multirow[b]{2}{*}{$\begin{array}{l}\text { Setores } \\
\text { Vendedores } \\
\text { (i) }\end{array}$} & $\begin{array}{c}\text { Setor } \\
1\end{array}$ & $z_{11}$ & $z_{12}$ & $\sum_{j=1}^{n} Z_{1 j}$ & $\mathrm{C}_{1}$ & $\mathrm{I}_{1}$ & $\mathrm{G}_{1}$ & $\mathrm{~B}_{1}$ & $\mathrm{Y}_{1}$ & $\mathrm{X}_{\mathrm{t}}$ \\
\hline & $\begin{array}{c}\text { Setor } \\
2\end{array}$ & $z_{n}$ & $z_{22}$ & $\sum_{j=1}^{n} Z_{2 j}$ & $c_{2}$ & $\mathrm{I}_{2}$ & $\mathrm{G}_{2}$ & $\mathrm{E}_{2}$ & $\mathrm{Y}_{2}$ & $\mathrm{X}_{2}$ \\
\hline \multicolumn{2}{|c|}{ Subtota1 } & $\sum_{i=1}^{n} Z_{i 1}$ & $\sum_{i=1}^{n} Z_{i 2}$ & $\sum_{i, j=1}^{n} Z_{i \ddot{j}}$ & $\sum_{i=1}^{n} C_{i}$ & $\sum_{i=1}^{n} I_{i}$ & $\sum_{i=1}^{n} G_{i}$ & $\sum_{i=1}^{n} E_{i}$ & $\sum_{i=1}^{n} Y_{i}$ & $\sum_{i=1}^{n} X_{i}$ \\
\hline \multicolumn{2}{|c|}{ Importaçōes } & $\mathrm{IM}_{\mathrm{i}}$ & $\mathrm{IM}_{2}$ & $\sum_{j=1}^{n} I M_{j}^{D I}$ & IMC & IMI & IMG & $\mathrm{IME}$ & $\mathrm{IM}^{2}$ & \\
\hline \multicolumn{2}{|c|}{ Tributos } & $\mathrm{N}_{1}$ & $\mathrm{~N}_{2}$ & $\sum_{i=1}^{n} N_{j}$ & $\mathrm{NC}$ & NI & NG & NE & $\mathrm{N}^{\mathrm{x}}$ & \\
\hline \multicolumn{2}{|c|}{ Salários } & $\mathrm{S}_{\mathrm{t}}$ & $\mathrm{S}_{2}$ & $\sum_{j=1}^{n} S_{j}$ & & & & & & \\
\hline \multicolumn{2}{|c|}{ Valor adiciona do } & $\mathrm{VA}_{1}$ & $\mathrm{VA}_{2}$ & $\sum_{j=1}^{n} V A_{j}$ & & & & & & \\
\hline \multicolumn{2}{|c|}{$\begin{array}{l}\text { Valor bruto da } \\
\text { produção }\end{array}$} & $\mathrm{X}_{1}$ & $\mathrm{X}_{2}$ & $\sum_{j=1}^{n} X_{j}$ & & & & & & \\
\hline
\end{tabular}

Fonte: Adaptado de Crócomo (1998).

Onde:

$z_{\mathrm{i}}$ : elementos da matriz $Z$, o fornecimento de insumos do setor $i$ para o setor $j$;

$C_{i}$ : fornecimento de insumos do setor i destinado ao consumo final privado;

$\mathrm{I}_{i}$ : fornecimento do setor $i$ destinado ao investimento privado;

$\mathrm{G}_{i}$ : fornecimento do setor $i$ destinado ao governo (consumo mais investimento do governo);

$E_{i}$ : fornecimento do setor $i$ destinado às exportações para o resto do mundo;

$Y_{i}$ : total da demanda final atendida pelo setor $i\left(C_{i}+I_{i}+G_{i}+E_{i}\right)$;

$\mathrm{X}_{\mathrm{i}}$ : produção bruta do setor $i$;

$\mathrm{Im}_{\mathrm{i}}$ : importação do setor $j$;

$S_{\text {: }}$ salários pagos pelo setor j no processo de sua produção;

$\mathrm{N}_{\mathrm{i}}$ : aluguéis, juros, lucros, tributos indiretos líquidos pagos pelo setor j;

$\mathrm{VA}_{\mathrm{j}}$ : valor adicionado $\left(L_{\mathrm{j}}+N_{\mathrm{j}}\right)$;

$\sum_{j=1}^{n} I M_{j}^{D l}$ : total das importações do setor $\mathrm{j}$, para a demanda intermediária;

IMC: importações destinadas a bens de consumo;

IMI: importações destinadas a bens de investimento;

IMG: importações destinadas aos gastos do governo;

IME: importações destinadas às exportações;

IMY: total das importações destinadas para a demanda final. 
Para obter o sistema de insumo-produto originalmente definido por Leontief, foi utilizada a abordagem da tecnologia baseada na indústria, que assume que a composição da produção de um dado setor pode ser alterada, porém esse setor mantém a sua participação constante no mercado dos bens que produz (MILLER; BLAIR, 2009). Para o desenvolvimento da matriz com tecnologia baseada na indústria, são definidas, inicialmente, as matrizes:

$$
L=(I-A)^{-1} Y
$$

A equação 1 refere-se ao enfoque setor $(X)$ por setor $(Y)$ com a tecnologia baseada na indústria. A é a matriz de coeficientes técnicos, calculada dividindo-se os elementos da matriz $Z$ pela produção total de cada setor. Esse enfoque é o que mais se aproxima do modelo original de Leontief. $L=(I-A)^{-1}$ é a matriz inversa de Leontief e $l_{i j}$ são seus elementos. ${ }^{1}$

\subsection{Proposta Metodológica para Estimativa do Saldo Emprego do Comércio Internacional}

No modelo básico de insumo-produto, a geração de empregos por exportações ocorre pelo impacto desse componente da demanda final sobre a estrutura produtiva. Os setores exportadores nacionais aumentam a produção para suprir a demanda exterior por bens e serviços nacionais. Considerando as ligações intersetoriais, os setores exportadores aumentam o consumo intermediário para alimentar seus processos produtivos, gerando, indiretamente, produção e emprego em outros setores da economia. Por outro lado, as importações para consumo intermediário fazem com que o setor importador nacional deixe de adquirir bens e serviços de outros setores do próprio país. Assim, não serão gerados empregos indiretos a partir do aumento de produção do setor importador. As importações para a demanda final (governo, famílias e formação bruta de capital fixo) causam diminuição de postos de trabalho por não ativarem a economia nacional para suprir suas necessidades. O efeito multiplicador é, assim, transferido para outros países como demanda final externa. É dentro dessa dinâmica que se realizará a análise proposta.

O saldo emprego do comércio internacional foi dividido em três partes, a saber:

a) geração de empregos por exportações: efeito da demanda externa sobre a estrutura produtiva nacional e gerando empregos diretos e indiretos;

Para conhecer detalhadamente as matrizes da contabilidade social do Brasil e a derivação da matriz de insumo-produto, ver Feijó et al. (2004). 
b) empregos não gerados por importações para o consumo intermediário: diminuição do número de empregos gerados na economia por efeito direto e indireto;

c) empregos não gerados por importações para a demanda final: as importações de bens e serviços finais diminuem o impacto sobre a estrutura produtiva da economia e o número de empregos diretos e indiretos gerados.

O cálculo dos empregos não gerados leva em consideração o pressuposto importante de que os bens e serviços poderiam ser produzidos internamente. Essa é uma limitação do estudo e são incorporados os pressupostos do uso da matriz de insumo-produto, tais como processos de produção que utilizam insumos em proporções fixas, mercados em concorrência perfeita, economias de escala constantes e oferta perfeitamente elástica de insumos.

Para a estimativa dos efeitos do comércio internacional sobre o emprego, foram utilizadas as 14 matrizes de insumo-produto do Brasil no período de 1990 a 2003, as quais possuem 42 setores e foram calculadas utilizando-se as contas nacionais do Brasil. Os dados utilizados neste estudo são das contas nacionais divulgados pelo Instituto Brasileiro de Geografia e Estatística (IBGE). As matrizes de insumo-produto do período de 1990 a 1996 foram obtidas no site do instituto, enquanto as matrizes do período de 1997 a 2003 foram estimadas utilizando a metodologia de Guilhoto e Sesso Filho (2005).

\subsubsection{Geração de Empregos por Exportações}

O efeito das exportações sobre o emprego é uma análise de impacto (geração de empregos), pois essas são um dos componentes da demanda final. A matriz $Z$ possui uma coluna referente aos valores de exportações por setor $(E)$, valores que são utilizados para estimar o impacto sobre o emprego na economia:

$$
\begin{gathered}
\Delta X=(I-A)^{-1} E \\
J=\hat{v} \Delta X
\end{gathered}
$$

Em que $\Delta X$ é a variação da produção necessária para produzir os bens e serviços exportados; $j$ é o vetor de exportações, ambos (nx1); E é um vetor (nx1) que representa o impacto sobre o emprego em número de pessoas ocupadas por setor; $\hat{\mathrm{V}}$ é uma matriz diagonal (nxn) cujos elementos da diagonal são, respectivamente, os coeficientes de emprego, que são obtidos dividindo-se, para cada setor, o número de pessoas ocupadas por setor $\left(V_{\mathrm{i}}\right)$ pela produção total do setor correspondente $\left(X_{\mathrm{i}}\right)$, isto é: 


$$
v_{i}=\frac{V_{i}}{X_{i}}
$$

\subsubsection{Empregos Não Gerados por Importações para a Demanda Final}

O cálculo do número de empregos não gerados por importações para a demanda final é uma análise de impacto, considerando que as importações para o componente demanda final $(M F)$ poderiam ser produzidas internamente. $\mathrm{O}$ impacto das importações para a demanda final $\left(I M_{F}\right)$ sobre o emprego é dado por:

$$
\begin{gathered}
\Delta X=(I-A)^{-1} I M_{F} \\
P E_{D F}=\hat{v} \Delta X
\end{gathered}
$$

em que $P E_{C F}$ é um vetor (nx1) que representa os empregos não gerados por importações para a demanda final (governo, famílias e investimento) e $\hat{V}$ é uma matriz diagonal (nxn) em que os elementos da diagonal são, respectivamente, os coeficientes de emprego definidos anteriormente.

\subsubsection{Empregos Não Gerados por Importações para o Consumo Intermediário}

Para estimar o efeito das importações para consumo intermediário sobre o emprego, pressupõe-se que a economia é capaz de produzir internamente os produtos e serviços importados. A matriz de importações para consumo intermediário setor por setor é obtida dentro da metodologia descrita em Guilhoto e Sesso Filho (2005), denominada $I M_{C I}$, a qual é somada à matriz $Z$ de consumo intermediário nacional:

$$
N=Z+H
$$

Utilizando a matriz $N$, pode-se recalcular a matriz de coeficientes técnicos com importações para consumo intermediário, denominada $C$, dividindo os elementos da coluna da matriz $N$ pela respectiva produção total de cada setor. $\mathrm{A}$ nova matriz inversa de Leontief contendo o efeito das importações é dada por:

$$
S=(I-C)^{-1}
$$

em que $S=(I-C)^{-1}$ é a nova matriz inversa de Leontief obtida com a matriz de coeficientes recalculada com importações para o consumo intermediário, sendo $\mathrm{s}_{\mathrm{ij}}$ seus elementos. 
Para obter o efeito das importações para consumo intermediário sobre o número de pessoas ocupadas nos setores da economia, calculam-se as diferenças entre a matriz de impacto estimada da forma tradicional $(L)$ (matriz de Leontief sem importações) e a matriz de impacto com importações internalizadas, matriz $(S)$. A matriz resultante $(K)$ possui os elementos $k_{i}$ :

$$
k_{i j}=l_{i j}-s_{i j}
$$

Estima-se, então, o número de empregos não gerados em cada setor causado pelas importações para o consumo intermediário:

$$
P E_{C I}=\hat{v} K Y
$$

em que $P E_{C l}$ é um vetor (nx1) que representa o impacto sobre o emprego (número de empregos em cada setor) causado pela diminuição de capacidade de geração de empregos por importações para o consumo intermediário.

\section{3 Índice de Mudança Estrutural do Emprego}

O índice de mudança estrutural (IME) é uma estimativa do efeito realocação causado pelos diversos fatores que influenciam o emprego, tais como mudança de tecnologia, comércio internacional e variações da demanda interna. O IME é calculado da seguinte forma:

$$
I M E=\left\{\sum\left|p_{i, t}-p_{i, t-1}\right|\right\} / 2
$$

em que $p_{i, t}$ e $p_{i, t-1}$ representam a participação de cada setor no número total de pessoas ocupadas na economia nos períodos $t$ e $t-1$, respectivamente.

O uso do valor em módulo (absoluto) garante que valores positivos e negativos não serão anulados quando somados. O somatório é dividido por dois para não incorrer em dupla contagem.

O IME pode estar entre zero (nenhuma mudança estrutural) e 100\% (total modificação estrutural do emprego). Quanto mais próximo de zero, significa estabilidade da participação dos setores no total de pessoas ocupadas na economia. Quanto maior o valor, maior a mudança estrutural e a variação da participação dos setores (PRODUCTIVITY COMMISSION, 1998).

\section{Resultados e Discussão}

A análise de impacto mostra resultados referentes ao número de empregos gerados/não gerados por exportações/importações de toda a economia. Os valo- 
res calculados representam os efeitos diretos e indiretos sobre o número de empregos formais e informais dos setores. Na Tabela 1 (ver Apêndice) são apresentados os resultados dos efeitos do comércio internacional sobre emprego da economia brasileira no período 1990-2003. O número de empregos gerados por exportações (linha 1) foi crescente no período 1990/93. A partir da valorização da moeda nacional, determinada pelo Plano Real em 1994, houve diminuição da geração de empregos, passando a crescer, novamente, no final da década, após a maxidesvalorização da moeda, em janeiro de 1999.

A diminuição de empregos por importações para consumo intermediário (linha 2) apresentou tendência declinante no período 1990/94 e cresceu a partir de 1995, alcançando mais de 5 milhões de empregos a partir de 1999. A diminuição de postos de trabalho por importações para consumo intermediário foi menos sensível à taxa de câmbio que a geração de empregos por exportações. A diminuição de empregos por importações para a demanda final (linha 3) apresentou valores crescentes até 1998, quando estabilizou em torno de 2 milhões de postos de trabalho. Os resultados mostram que a maior parte dos empregos não gerados ocorreu por importações para consumo intermediário e não pelas importações para a demanda final. O saldo de empregos do comércio internacional (linha 4) foi negativo no período 1990-2001, melhorando a partir 1999, com a desvalorização da moeda, e se tornando positivo nos anos 2002 e 2003.

As linhas 5 e 6 da Tabela 2 (ver Apêndice) apresentam, respectivamente, o número de pessoas ocupadas na economia e a relação saldo de empregos do comércio internacional e número de pessoas ocupadas. No período 1990-1994, apesar do saldo positivo da balança comercial, o saldo de empregos foi negativo. A pauta de exportações, concentrada em commodities, e as importações de produtos com maior valor agregado explicam o fenômeno. Entre 1995 e 1998 ocorreu déficit da balança comercial e o saldo negativo permaneceu acima de 3,5\% do número de pessoas ocupadas na economia, recuperando-se a partir de 1999.

A Tabela 2 (ver Apêndice) apresenta o índice de modificação estrutural do emprego (IME) calculado para o número de pessoas ocupadas nos setores (linha 1) e para a variações do saldo do emprego do comércio internacional (linha 2). Os índices mostram a variação da participação dos setores no número de pessoas ocupadas na economia, sendo o primeiro o resultado de fatores internos e externos, enquanto o segundo reflete a variação causada pelo comércio internacional. Ambos podem ser interpretados como proxy da instabilidade do mercado de trabalho, mostrando o efeito de realocação intersetorial dos postos de trabalho na economia.

Os resultados evidenciam que as maiores transformações ocorreram no ano de 1995, com 3,65\% para o pessoal ocupado e 1,18\% para o índice de comércio internacional. Os anos de 1999 e 2002 também apresentam altos valores para o 
índice de modificação estrutural do emprego causada pelo comércio internacional. No ano de 1999, ocorreu a desvalorização do câmbio, gerando modificações na balança comercial e realocação do emprego dos setores prejudicados (importadores) para os beneficiados (exportadores). O ano de 2002 marcou o início de uma fase de melhora significativa da balança comercial, causada pela desvalorização da moeda, pelo aumento da competitividade dos setores e pela melhora dos preços das commodities, influenciando de forma mais forte o emprego setorial e se tornando mais importante que os fatores internos (o índice para o comércio internacional, 1,29\%, foi maior do que $1,02 \%$ do índice geral). Isso pode ocorrer porque o comércio externo pode beneficiar/prejudicar setores que serão compensados por efeitos internos.

A Tabela 3 (ver Apêndice) apresenta a participação de grupos de setores no número de pessoas ocupadas na economia no período 1990-2003. Ao longo do período, a agropecuária e a indústria perderam participação no número de postos de trabalho, ao passo que a participação dos setores comércio e serviços aumentou, como resultado de vários fatores, internos e externos. Os resultados da presente pesquisa mostram, para o período 1990-2003, que houve variação gradual da participação dos grupos de setores no número de pessoas ocupadas e as maiores transformações coincidem com maiores impactos dos fluxos de comércio sobre o emprego, não sendo elas negligenciáveis.

As Tabelas 4, 5 e 6 (ver Apêndice) resumem os resultados do saldo emprego do comércio internacional para os anos de 1990, 1996 e 2003 por setores da economia. A seguir, as Figuras 1 e 2 ilustram, respectivamente, os resultados comparados entre 1990 e 1996 e os valores obtidos para os anos de 1996 e 2003. É importante observar que os valores são obtidos em equilíbrio geral, considerando os empregos diretos e indiretos. 
Figura 1 - Relação percentual entre saldo de empregos e número de pessoas ocupadas nos setores (Brasil, 1990 e 1996)

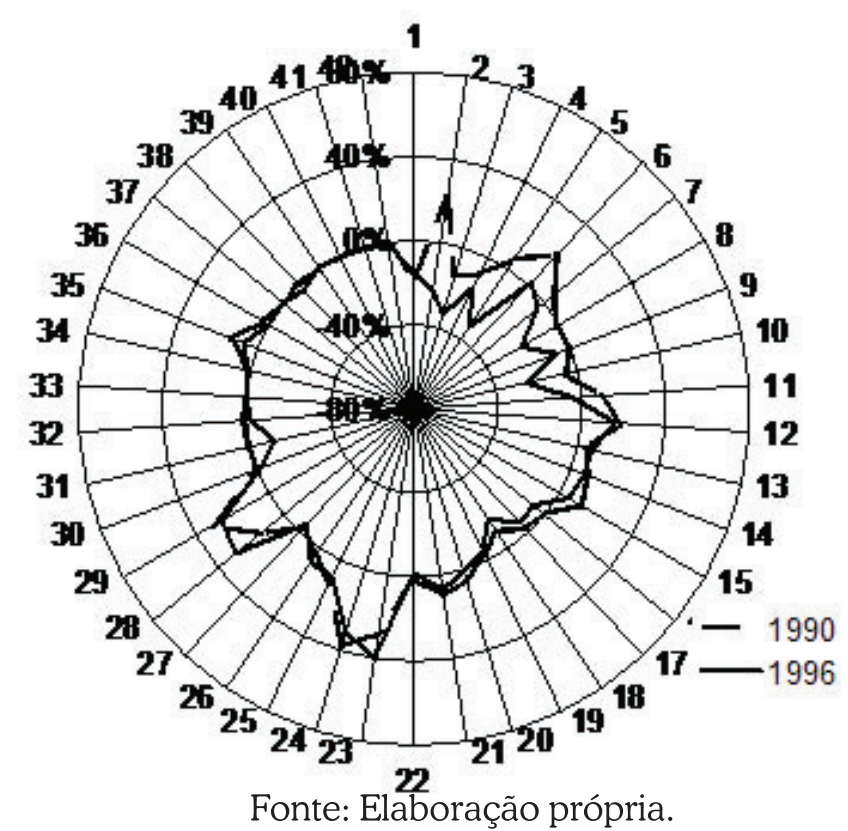

Figura 2 - Relação percentual entre saldo de empregos e número de pessoas ocupadas dos setores (Brasil, 1996 e 2003)

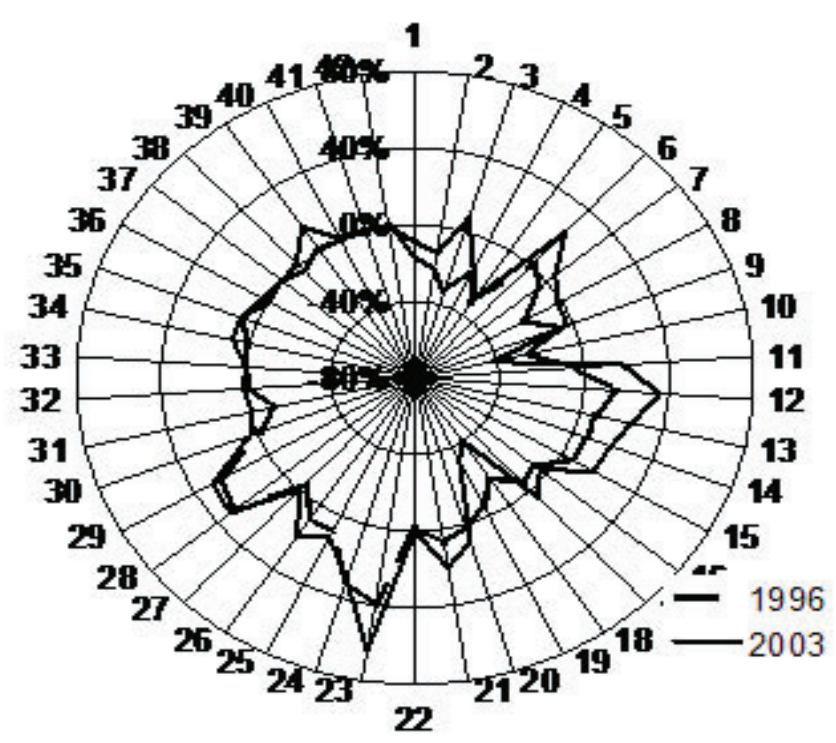

Fonte: Elaboração própria.

Em 1990, o comércio exterior do Brasil gerou, via exportações, cerca de 4,1 milhões de empregos, enquanto a diminuição de empregos por importações foi de, aproximadamente, 6 milhões, resultando em saldo negativo de, aproximadamente, 1,9 milhão de postos de trabalho, o que representou cerca de $3 \%$ das pessoas ocupadas no país. Os resultados mostram que, em 1990, as maiores perdas de empregos ocorrem por importações para consumo intermediário, característica que permanece em todo o período da análise. A análise dos resultados na Figura 
1 mostra que houve aumento da perda de empregos em valores percentuais da maior parte dos setores da economia entre 1990 e 1996. No período 1996 a 2003, mostrado na Figura 2, pode-se observar que os setores apresentam saldos positivos de emprego devido ao comércio internacional.

Os três setores que apresentaram os maiores percentuais de saldo negativo de empregos em 1990 são: 1-Agropecuária, 3-Petróleo e gás e 18-Químicos diversos. Esses são importantes fornecedores de insumos para outras indústrias. Portanto, o menor efeito indireto sobre o emprego da economia causado por importações, principalmente consumo intermediário, influencia de forma importante o número de postos de trabalho nessas atividades. As indústrias que possuem os maiores percentuais de saldo positivo de empregos são: 24-Indústria do café, 29-Fabricação de óleos vegetais, 23-Fabricação de calçados, 2-Extrativismo mineral, 6-Metalurgia de não ferrosos e 12-Peças e outros veículos. Esses setores estão ligados diretamente ao comércio internacional, exportando seus produtos e gerando empregos diretos e indiretos. No caso específico da 24-Indústria do café, aproximadamente $38 \%$ dos empregos da atividade dependiam das exportações da economia no ano de 1990. Outro resultado importante foi que o emprego nos setores de 34-Comércio e 35-Transportes apresentou saldo positivo.

Os resultados do saldo emprego do comércio internacional dos setores no ano de 1996 mostram a geração de 4 milhões de empregos por exportações e diminuição de 6,3 milhões de postos de trabalho por importações. O saldo negativo de -2,3 milhões nesse ano foi maior que os -1,9 milhões em 1990. No período 19901996, aumentou a importância dos empregos não gerados por importações para a demanda final, que totalizaram cerca de 1,7 milhões de empregos, em 1996, e eram de 0,88 milhões seis anos antes. Os setores apresentaram situação pior do saldo do emprego no período 1990-1996. Os déficits foram maiores para os setores 1-Agropecuária, 2-Extrativismo mineral, 3-Petróleo e gás, 4-Mineral não metálico, 5-Siderurgia, 8-Máquinas e equipamentos, 10-Equipamentos eletrônicos e 18-Químicos diversos.

Em 2003, ocorreu geração de, aproximadamente, 8,4 milhões de empregos, 7 milhões de empregos deixaram de ser gerados e o saldo positivo foi de 1,4 milhões de postos de trabalho, representando cerca de $2 \%$ do número de pessoas ocupadas. É importante observar que o número de empregos não gerados por importações aumentou no período 1996-2003, porém, o número de empregos gerados pelas exportações superou de forma expressiva (mais que dobrou), resultando em saldo positivo. Os resultados refletem os efeitos da desvalorização da moeda nacional ocorrida em 1999. Os setores que apresentaram maiores saldos percentuais negativos de emprego no ano de 2003 foram: 10-Equipamentos eletrônicos, 18-Químicos diversos, 19-Farmácia e veterinária, 5-Siderurgia, 4-Mineral não metálico, 2-Extrativismo mineral e 1-Agropecuária. Os setores 10-Equipamen- 
tos eletrônicos e 19-Farmácia e veterinária foram prejudicados por importações para a demanda final, enquanto os outros citados sofreram impacto maior por importações para consumo intermediário. Por outro lado, as atividades que foram beneficiadas pelo comércio internacional em relação ao emprego após a desvalorização da moeda nacional em 1999 foram: 23-Fabricação de calçados, 12-Peças e outros veículos, 32-Fabricação de açúcar, 29-Fabricação de óleos vegetais, 24-Indústria do café, 13-Madeira e mobiliário e 6-Metalurgia de não ferrosos.

\section{Considerações Finais}

Os resultados obtidos pela aplicação da metodologia proposta para estimar os impactos sobre a geração de emprego do comércio internacional se mostraram coerentes com a situação econômica do Brasil no período 1990-2003. As estimativas do impacto do comércio internacional sobre o emprego mostraram que as importações para consumo intermediário têm maior efeito sobre o número de postos de trabalho na economia que as importações para a demanda final. No período de análise, houve queda da participação da indústria no número total de postos de trabalho, indicando um processo de desindustrialização e maior dependência de insumos importados. Esse efeito está presente nos resultados da aplicação da metodologia como perda de postos de trabalho dos setores por importações para consumo intermediário da indústria.

Os maiores efeitos sobre a variação de postos de trabalho na economia e realocação intersetorial foram causados pelo Plano Real, principalmente no período 1994-1996. As medidas tomadas determinaram um custo-emprego, entre 1994-1995, de 1,38 milhões de postos de trabalho, correspondendo a 2,25\% do pessoal ocupado em 1995. O principal setor prejudicado pelo balanço do emprego do comércio exterior foi a agropecuária, que apresentou saldo negativo de 2,2 milhões de empregos, em 1996, perfazendo cerca de 16\% do número de postos de trabalho nesse setor. Os setores extrativismo mineral, petróleo e gás, siderurgia, mineral não metálico, equipamentos eletrônicos, máquinas e equipamentos e químicos diversos foram altamente prejudicados no período de grandes fluxos de importações entre 1995 e 1998. Os setores do agronegócio, tais como indústria do café, indústria de óleos vegetais e fabricação de açúcar apresentaram saldos positivos de emprego, mesmo nesse período.

A desvalorização da moeda nacional em 1999 beneficiou a geração de postos de trabalho por exportações que superou a perda de empregos no ano de 2002. No ano de 2003, o saldo do emprego torna-se positivo em 1,4 milhão de postos de trabalho, aproximadamente $2,1 \%$ do pessoal ocupado. Isso mostra a recuperação da balança comercial, impulsionada pela desvalorização da moeda e por preços internacionais favoráveis. Os setores mais beneficiados foram os ligados 
ao agronegócio, como madeira e mobiliário, fabricação de óleos vegetais e fabricação de açúcar.

Os resultados indicam a necessidade de agregar valor aos produtos exportados, o que aumentaria o efeito multiplicador de emprego nas cadeias produtivas e a capacidade de geração de postos de trabalho das exportações. Além disso, altos valores de perda de empregos por importações para consumo intermediário (insumos) mostram a necessidade de desenvolver as cadeias produtivas nacionais e novas tecnologias para diminuir a dependência externa para abastecimento dos setores e evitar o processo de desindustrialização.

Novos estudos sobre os impactos sobre o emprego causados pelo comércio internacional devem contemplar um período mais recente de análise para o Brasil. Porém, é importante considerar que existe defasagem temporal na divulgação da matriz de insumo-produto pelo IBGE, que é o órgão responsável pela elaboração das contas nacionais. A metodologia pode ser utilizada também para outros países, pois o sistema de contas nacionais apresenta padronização internacional. Dessa forma, podem ser realizadas comparações em valores relativos para a economia e também para setores, desde que estes sejam os mesmos entre as economias.

\section{Referências}

BAER, W. A economia brasileira. São Paulo: Nobel, 2003. 512 p.

CROCOMO, F. C. Análise das relações inter-regionais e intersetoriais na economia brasileira em 1985: uma aplicação de insumo-produto. 1998. Tese (Doutorado em Economia) - Escola Superior de Agricultura Luz de Queiroz, Universidade de São Paulo, 1998.

FEIJÓ, C. A. et al. Contabilidade social: o novo sistema de contas nacionais do Brasil. Rio de Janeiro: Campus, 2004. 413 p.

GREMAUD, A. P.; VASCONCELOS, M. A. S.; TONETO JR., R. Economia brasileira contemporânea. São Paulo: Atlas, 2007. 672 p.

GUILHOTO, J. J. M.; SESSO FILHO, U. A. Estimação da matriz insumo-produto a partir de dados preliminares das Contas Nacionais. Revista de Economia Aplicada, v. 9, n. 2, p. 277299, abr.jun. 2005.

INSTITUTO DE PESQUISA ECONÔMICA APLICADA - Ipea. Ipeadata. Disponível em: $<$ http://www.ipeadata.gov.br>. Acesso em: 20 maio 2010.

MILLER, R. E.; BLAIR, P. D. Input-output analysis: foundations and extensions. New York: Cambrige University Press, 2009. 750 p.

MOREIRA, M. M.; NAJBERG, S. O impacto da abertura comercial sobre o emprego: 19901997. In: GIAMBIAGI, F.; MOREIRA, M. M. (Org.). A economia brasileira nos anos 90. Rio de Janeiro: BNDES, 1999. 488p.

PRODUCTIVITY COMMISSION. Aspects of structural change in Australia. Canberra: Research Report, AusInfo, 1998. 
SOARES, S.; SERVO, L. M. S.; ARBACHE, J. S. O que (não) sabemos sobre a relação entre abertura comercial e mercado de trabalho no Brasil. Rio de Janeiro: Ipea, 2001. (Texto para discussão, 843). Disponível em: <http://www.ipea.gov.br>. Acesso em: 15 jul. 2010. 


\section{Apêndice}
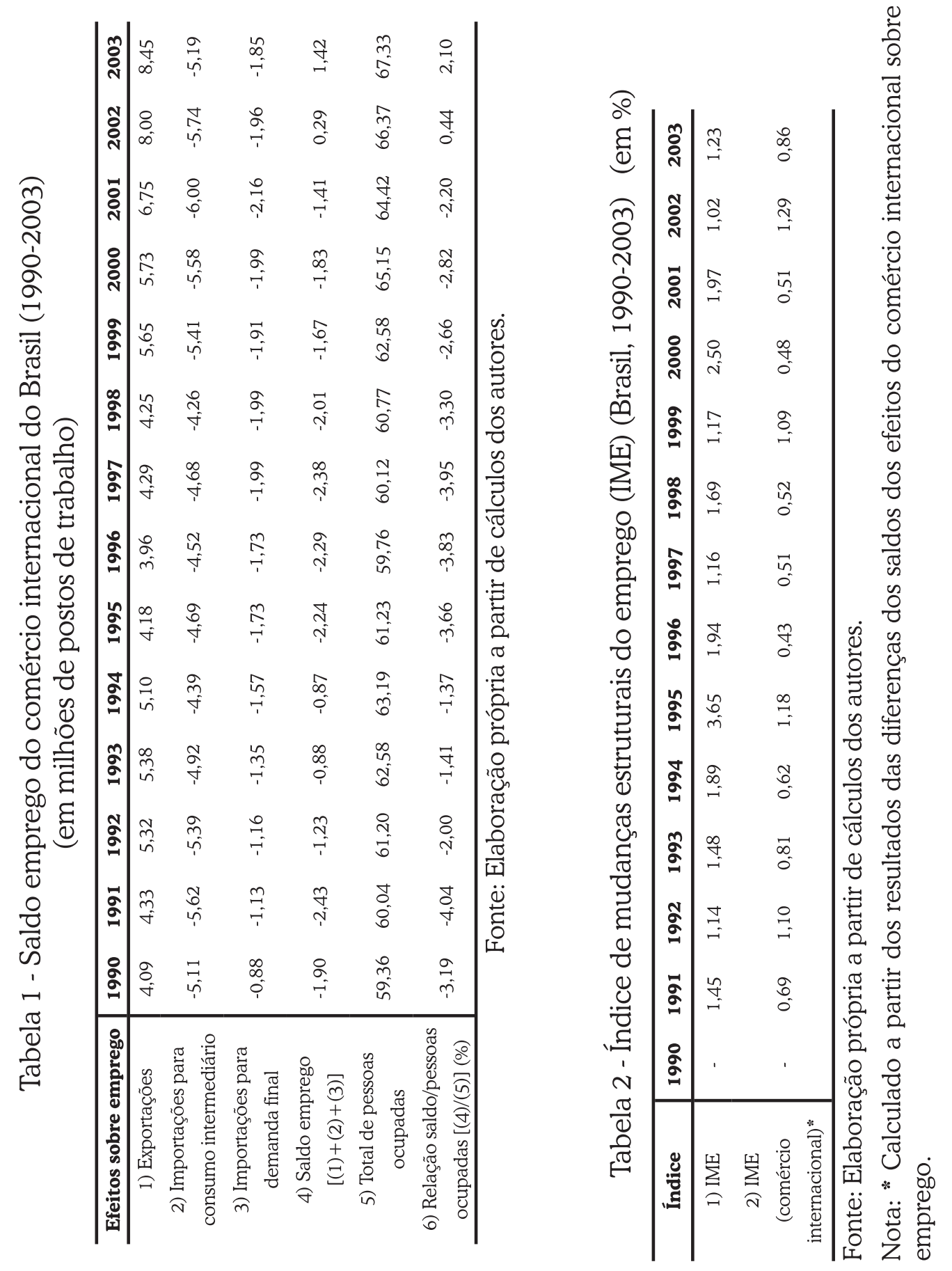


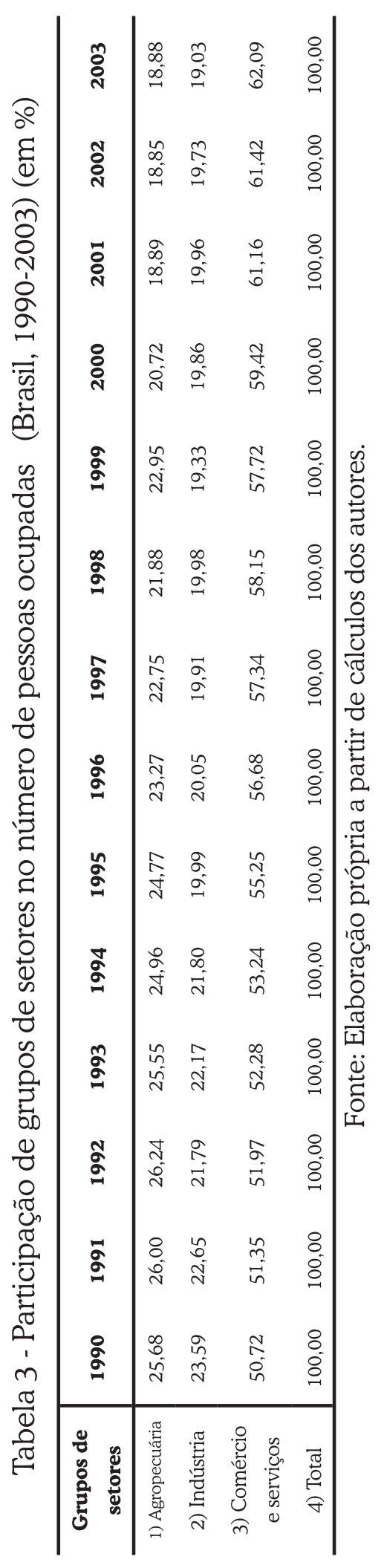


Tabela 4 - Saldo emprego do comércio internacional do Brasil em pessoas ocupadas por setor no ano de 1990

\begin{tabular}{|c|c|c|c|c|c|}
\hline \multirow[b]{2}{*}{ Setor } & \multicolumn{5}{|c|}{ Número de postos de trabalho (milhares) } \\
\hline & Exportações & $\begin{array}{c}\text { Importações } \\
\text { consumo } \\
\text { intermediário }\end{array}$ & $\begin{array}{c}\text { Importações } \\
\text { demaanda } \\
\text { final }\end{array}$ & Saldo & $\begin{array}{l}\text { Relação saldo/pessoas } \\
\text { ocupadas no setor }\end{array}$ \\
\hline 2 Extrativismo mineral & 164 & 92 & 5 & 68 & $22 \%$ \\
\hline 3 Petróleo e gás & 7 & 10 & 3 & -6 & $-14 \%$ \\
\hline 5 Siderurgia & 58 & 44 & 5 & 9 & $6 \%$ \\
\hline 6 Metalurgia de não ferrosos & 28 & 10 & 3 & 15 & $20 \%$ \\
\hline 7 Outros metalúrgicos & 105 & 42 & 26 & 38 & $6 \%$ \\
\hline 8 Máquinas e equipamentos & 87 & 40 & 56 & -9 & $-2 \%$ \\
\hline 12 Peças e outros veículos & 72 & 6 & 11 & 55 & $19 \%$ \\
\hline 13 Madeira e mobiliário & 63 & 14 & 8 & 40 & $4 \%$ \\
\hline 14 Celulose, papel e gráfica & 64 & 14 & 10 & 40 & $9 \%$ \\
\hline 15 Indústria da borracha & 17 & 4 & 2 & 11 & $12 \%$ \\
\hline 16 Elementos químicos & 12 & 10 & 2 & -1 & $-1 \%$ \\
\hline 17 Refino do petróleo & 15 & 15 & 2 & -2 & $-2 \%$ \\
\hline 18 Químicos diversos & 27 & 42 & 4 & -19 & $-10 \%$ \\
\hline 19 Farmácia e veterinária & 4 & 7 & 1 & -4 & $-3 \%$ \\
\hline $\begin{array}{l}25 \text { Beneficiamento de produtos } \\
\text { vegetais }\end{array}$ & 51 & 3 & 9 & 38 & $12 \%$ \\
\hline 26 Abate de animais & 16 & 1 & 6 & 9 & $4 \%$ \\
\hline 27 Indústria de laticínios & 1 & 0 & 2 & -2 & $-3 \%$ \\
\hline 28 Fabricação de açúcar & 13 & 2 & 1 & 11 & $14 \%$ \\
\hline 29 Fabricação de óleos vegetais & 18 & 2 & 1 & 16 & $31 \%$ \\
\hline 30 Outros produtos alimentares & 34 & 24 & 11 & -2 & $0 \%$ \\
\hline 31 Indústrias diversas & 38 & 18 & 18 & 2 & $1 \%$ \\
\hline 32 Serviços industriais de utilidade & 27 & 16 & 5 & 6 & $2 \%$ \\
\hline 33 Construção civil & 12 & 5 & 3 & 4 & $0 \%$ \\
\hline 34 Comércio & 406 & 219 & 73 & 113 & $1 \%$ \\
\hline 35 Transportes & 383 & 82 & 45 & 255 & $13 \%$ \\
\hline 36 Comunicações & 16 & 6 & 3 & 7 & $3 \%$ \\
\hline 37 Instituições financeiras & 7 & 4 & 5 & -1 & $0 \%$ \\
\hline 38 Serviços prestados à família & 298 & 51 & 208 & 39 & $1 \%$ \\
\hline 39 Serviços prestados à empresa & 79 & 44 & 20 & 16 & $1 \%$ \\
\hline
\end{tabular}

Fonte: Elaboração própria a partir de cálculos dos autores. 
Tabela 5 - Saldo emprego do comércio internacional do Brasil em pessoas ocupadas por setor no ano de 1996

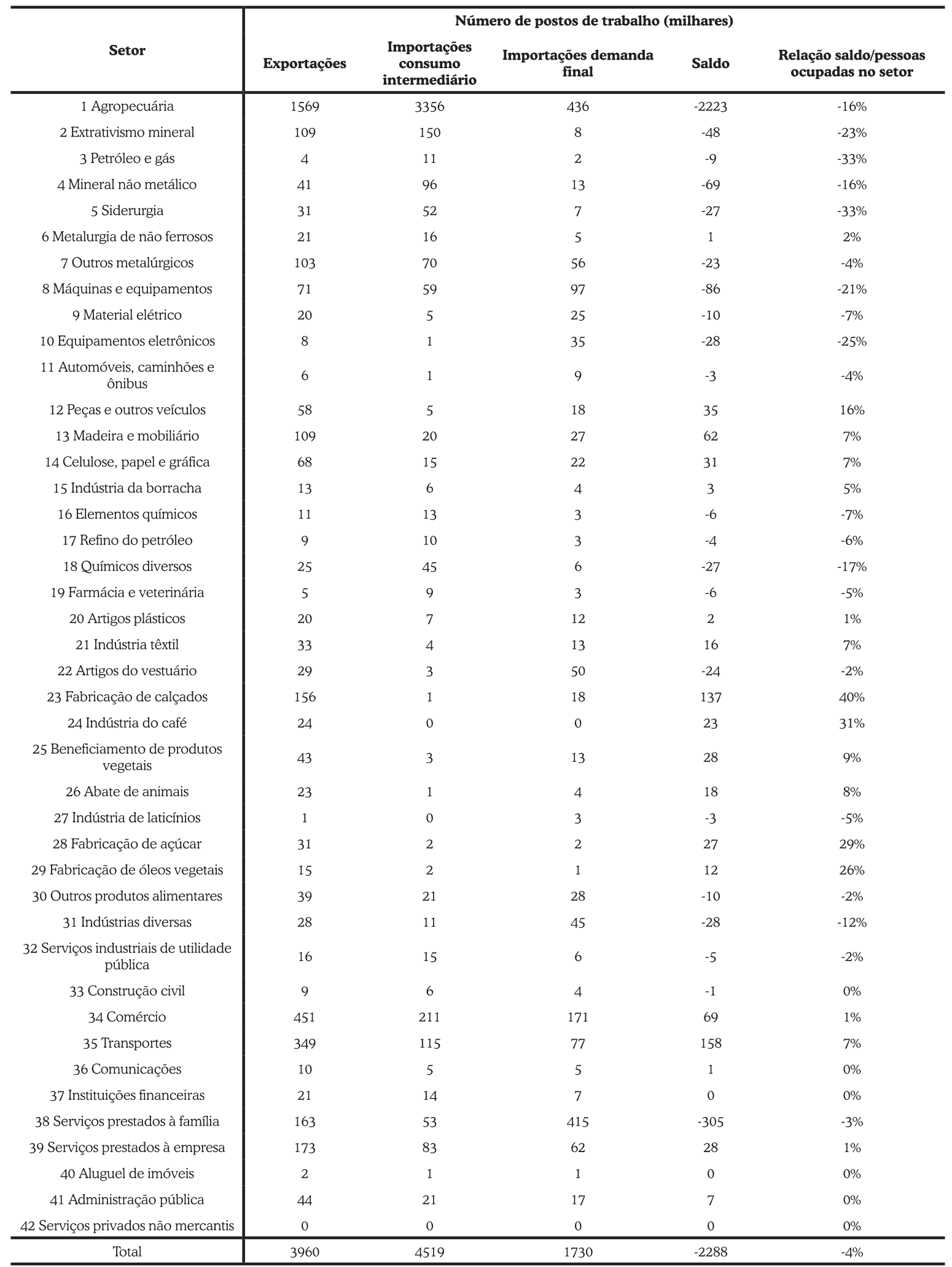

Fonte: Elaboração própria a partir de cálculos dos autores. 
Tabela 6 - Saldo emprego do comércio internacional do Brasil em pessoas ocupadas por setor no ano de 2003

\begin{tabular}{|c|c|c|c|c|c|}
\hline \multirow[b]{2}{*}{ Setor } & \multicolumn{5}{|c|}{ Número de postos de trabalho (milhares) } \\
\hline & Exportações & $\begin{array}{c}\text { Importações } \\
\text { consumo } \\
\text { intermediário }\end{array}$ & $\begin{array}{l}\text { Importações } \\
\text { demanda final }\end{array}$ & Saldo & $\begin{array}{l}\text { Relação saldo/ } \\
\text { pessoas ocupadas } \\
\text { no setor }\end{array}$ \\
\hline 1 Agropecuária & 2590 & 3414 & 310 & -1134 & $-9 \%$ \\
\hline 2 Extrativismo mineral & 179 & 206 & 7 & -34 & $-14 \%$ \\
\hline 3 Petróleo e gás & 21 & 14 & 3 & 4 & $7 \%$ \\
\hline 4 Mineral não metálico & 60 & 115 & 12 & -67 & $-17 \%$ \\
\hline 5 Siderurgia & 38 & 58 & 5 & -25 & $-30 \%$ \\
\hline 6 Metalurgia de não ferrosos & 30 & 10 & 5 & 15 & $24 \%$ \\
\hline 7 Outros metalúrgicos & 174 & 84 & 54 & 35 & $5 \%$ \\
\hline 8 Máquinas e equipamentos & 133 & 58 & 87 & -12 & $-2 \%$ \\
\hline 9 Material elétrico & 28 & 3 & 28 & -4 & $-3 \%$ \\
\hline 10 Equipamentos eletrônicos & 33 & 1 & 73 & -41 & $-43 \%$ \\
\hline 11 Automóveis, caminhões e ônibus & 20 & 1 & 6 & 13 & $18 \%$ \\
\hline 12 Peças e outros veículos & 106 & 4 & 21 & 81 & $36 \%$ \\
\hline 13 Madeira e mobiliário & 275 & 17 & 27 & 231 & $25 \%$ \\
\hline 14 Celulose, papel e gráfica & 114 & 17 & 17 & 80 & $19 \%$ \\
\hline 15 Indústria da borracha & 17 & 5 & 3 & 9 & $17 \%$ \\
\hline 16 Elementos químicos & 19 & 19 & 3 & -3 & $-4 \%$ \\
\hline 17 Refino do petróleo & 14 & 9 & 2 & 3 & $5 \%$ \\
\hline 18 Químicos diversos & 37 & 91 & 7 & -61 & $-41 \%$ \\
\hline 19 Farmácia e veterinária & 8 & 12 & 34 & -37 & $-32 \%$ \\
\hline 20 Artigos plásticos & 46 & 11 & 16 & 19 & $9 \%$ \\
\hline 21 Indústria têxtil & 60 & 4 & 9 & 46 & $20 \%$ \\
\hline 22 Artigos do vestuário & 40 & 2 & 37 & 1 & $0 \%$ \\
\hline 23 Fabricação de calçados & 275 & 2 & 16 & 257 & $64 \%$ \\
\hline 24 Indústria do café & 21 & 0 & 0 & 21 & $30 \%$ \\
\hline 25 Beneficiamento de produtos vegetais & 53 & 4 & 11 & 38 & $12 \%$ \\
\hline 26 Abate de animais & 49 & 1 & 2 & 46 & $20 \%$ \\
\hline 27 Indústria de laticínios & 1 & 0 & 1 & 0 & $-1 \%$ \\
\hline 28 Fabricação de açúcar & 30 & 3 & 1 & 26 & $32 \%$ \\
\hline 29 Fabricação de óleos vegetais & 14 & 2 & 1 & 11 & $30 \%$ \\
\hline 30 Outros produtos alimentares & 70 & 29 & 25 & 16 & $3 \%$ \\
\hline 31 Indústrias diversas & 56 & 16 & 43 & -3 & $-1 \%$ \\
\hline $\begin{array}{l}32 \text { Serviços industriais de utilidade } \\
\text { pública }\end{array}$ & 28 & 17 & 9 & 2 & $1 \%$ \\
\hline 33 Construção civil & 21 & 9 & 5 & 7 & $0 \%$ \\
\hline 34 Comércio & 1822 & 581 & 287 & 954 & $8 \%$ \\
\hline 35 Transportes & 468 & 166 & 74 & 228 & $8 \%$ \\
\hline 36 Comunicações & 25 & 8 & 9 & 8 & $3 \%$ \\
\hline 37 Instituições financeiras & 34 & 17 & 16 & 2 & $0 \%$ \\
\hline 38 Serviços prestados à família & 623 & 23 & 440 & 159 & $2 \%$ \\
\hline 39 Serviços prestados à empresa & 746 & 139 & 120 & 487 & $15 \%$ \\
\hline 40 Aluguel de imóveis & 4 & 2 & 1 & 2 & $1 \%$ \\
\hline 41 Administração pública & 71 & 18 & 17 & 37 & $1 \%$ \\
\hline 42 Serviços privados não mercantis & 0 & 0 & 0 & 0 & $0 \%$ \\
\hline Total & 8455 & 5192 & 1847 & 1416 & $2 \%$ \\
\hline
\end{tabular}

Fonte: Elaboração própria a partir de cálculos dos autores.

Recebido em: 28/07/2011.

Aceito em: 14/06/2012. 